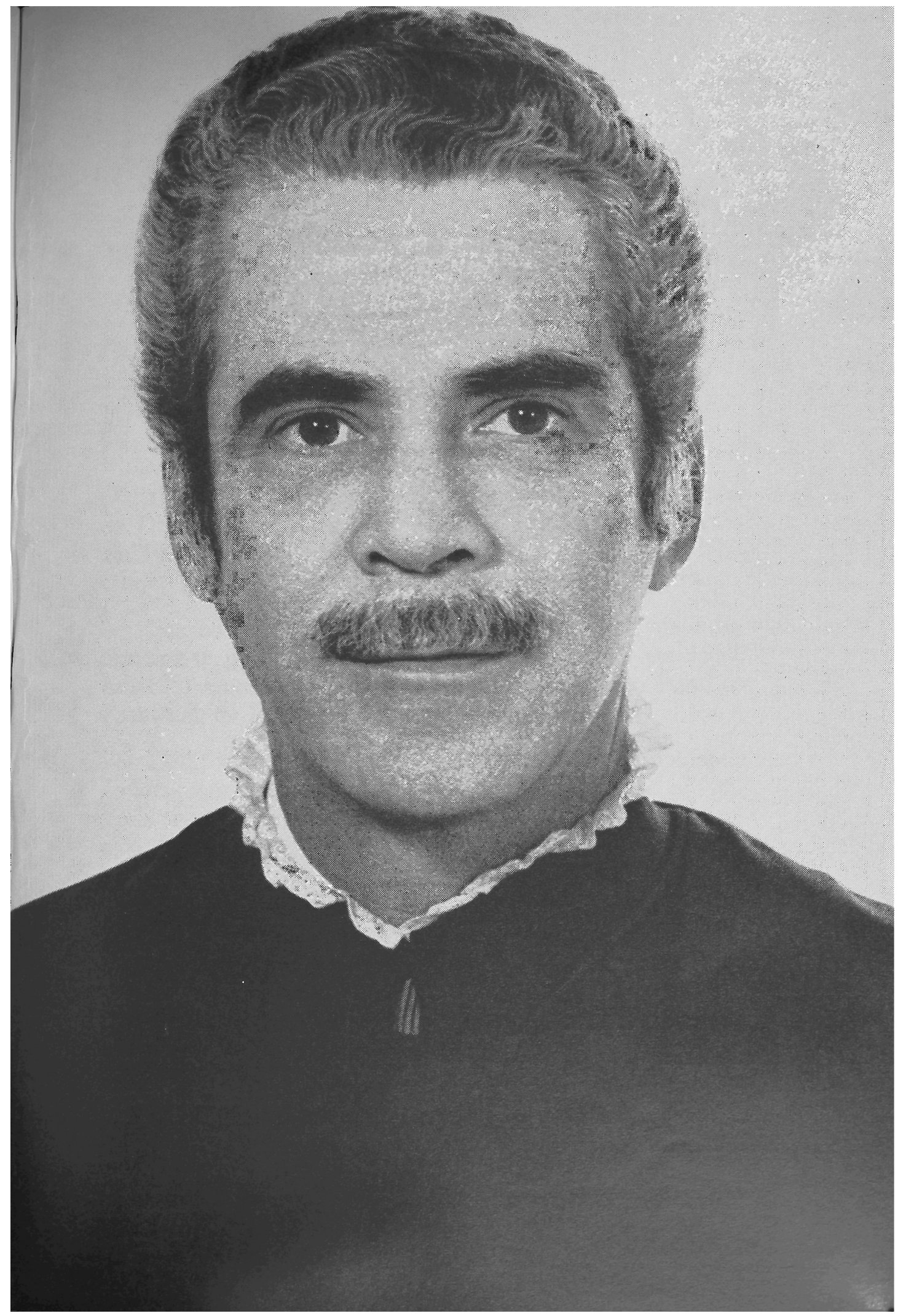


Professor Doutor Joāo Bernardino Garcia Gonzaga, Titular de Direito Penal. 


\section{O Novo Titular de Direito Penal, João Bernardino Garcia Gonzaga.}

A Redação

O dr. João Bernardino Garcia Gonzaga, novo titular de Direito Penal, nasceu em Pirajuí, Estado de São Paulo, aos 19 de abril de 1927. Filho do Desembargador João Marcelino Gonzaga e de d. Zalina Garcia Gonzaga.

Fez os estudos secundários no Colégio São Luiz e bacharelou-se pela Faculdade de Direito da U.s.P. em 1950. Em 1951 seguiu curso de doutoramento em Direito Penal na Faculdade de Direito de Paris.

Dedicou-se sempre à advocacia, em São Paulo. Foi chefe do Departamento Legal do "The National City Bank of New York" e membro do Conselho Consultivo do Instituto Jurídicor da Associação Comercial de S. Paulo.

Iniciou sua carreira docente na Faculdade de Direito da U.S.P em 1954, como auxiliar de ensino. Em 1957, foi aprovado em concurso para livre docente de Direito Penal. Em 1973, através de concurso de títulos, tornou-se Professor adjunto: da mesma disciplina. E, atualmente, o chefe do Departamento de Direito Penal.

Em 1955, foi também designado assistente da cadeira de Direito Penal na Faculdade Paulista de Direito da Pontifícia Universidade Católica de São Paulo, passando a Pro- 
fessor contratado em 1958. Aprovado em concurso, foi provido na cátedra de Direito Penal em 1964. De 1968 a 1972, exerceu a Diretoria dessa Faculdade.

Participou de inúmeros congressos, no Brasil e no exterior, e tem figurado como examinador em vários concursos jurídicos. Em 1971, foi designado pelo sr. Ministro da Justiça para proceder à revisão do Código Penal de 1969. Por decreto de abril de 1975, o Governador de São Paulo o nomeou para compor Grupo de Trabalho constituído a fim de oferecer "sugestões relativas à reforma do sistema de penas e outras que possibilitem o encaminhamento da solução para o' premente problema carcerário do Estado" E acadêmico suplente da Academia Paulista de Direito e Presidente do Instituto de Ciências Penais, seção de S. Paulo.

Casado com d. Jeanine Louise Gonzaga, tem os filhos Paula, Marta Maria, João Marcelino e Luiz Henrique.

Além de vários cursos e conferências, publicou os seguintes trabalhos:

1. O Crime de Omissão de Socorro, S. Paulo, 1957.

2. Elementos de Gramática Francesa para o Concurso de Habilitação aos Cursos Superiores, S. Paulo, 1961.

3. Simulação da Qualidade de Funcionário Público, Revista dos Tribunaís, S. Paulo, 1960, v. 297.

4. Crimes Comissivos por Omissão, em Estudos de Direito e Processo Penal em Homenagem a Nelson Hungria, Rio, 1962.

5. Entorpecentes, Aspectos Criminológicos e Jurídico-Penais, S. Paulo, 1963.

6. Do Crime de Abandono da Familia, Revista dos Tribunais, S. Paulo, 1966, v. 374 .

7. O Crime de Sonegação Fiscal, Revista dos Tribunais, S. Paulo, 1967, v. 380.

8. Tentativa, Revista Brasileira de Direito Penal e Criminologia, Rio, 1965, v. 9 .

9. Direito Penal Internacional, Revista da Univ. Católica de S. Paulo, v. XXXVIII, 1970 , f. 73 e 74 . 
10. O Direito Penal Indigena à Epoca do Descobrimento do Brasil, S. Paulo, 1971 .

11. Concurso de Crimes. O Criminoso por Tendência e o Habitual, publ. nos Anais do Ciclo de Conferências sobre o Novo Código Penal, da Assoctação dos Advogados de S. Paulo, 1972.

12. Consideraçóes sobre o Pensamento da Escola Positiva, em Ciência Penal, S. Paulo, 1974, f. 3 .

13. O Direito Penal dos Povos Primitivos, na Revista da Faculdade de Direito, S. Paulo, 1973, v. LXVIII.

14. Violação de Segredo Profissional, S. Paulo, 1975.

\section{A Congregação dos Professores recebe o Novo Titular.}

Com a tese Violação de Segredo Profissional, João Bernardino Garcia Gonzaga submete-se a concurso para a titularidade da Cadeira de Direito Penal, vaga pela aposentadoria do Professor Basileu Garcia.

Aprovado por unanimidade, é nomeado a 12 de agosto e recebido pela Congregação dos professores, em sessão solene realizada no salão nobre a 14 de setembro deste ano.

Aberta a solenidade pelo presidente da mesa, o senhor Diretor da Faculdade Professor Ruy Barbosa Nogueira, João Bernardino Garcia Gonzaga é introduzido no doutoral pelos professores Canuto Mendes de Almeida, Goffredo Telles Júnior e Washington de Barros Monteiro.

Toma a palavira, então, o professor José Cretella Júnior, que em curta oração faz o panegírico do novo titular.

\section{Oração de José Cretella Júnior.}

\section{João Bernardino Garcia Gonzaga.}

Há muitos anos assisti a uma sessão solene na Academia Brasileira de Letras. Tratava-se da cerimônia de posse de novo acadêmico. 
O acadêmico mais antigo, encarregado de receber o irmão imortal, o saudava gongoricamente e dizia: "Quando se atinge a idade em que o verdor das ilusões começa a fenecer ao sopro esterilizante das paixões ingratas. a vida" - e foi por aí afora durante duas longas e intermináveis horas.

A resposta do homienageado em nada desmereceu, quantitativamente, à saudação proferida. Superou-a mesmo. Duas horas e meia.

O auditório saiu cansado e eu prometi, desse dia em diante, nunca trazer laudas e laudas de papel, amedrontando o auditório e esparramando sobre os ouvintes a epidemia contagiante do bocejo.

Por isso, não me surpreendi quando mais tarde, num diálogo, ouvi dum futuro homenageado. "Prefiro ser decapitado. O suplício é mais rápido do que o de ouvir uma fileira de discursos longos"

Podem, pois, os senhores, e pode esta douta Congregação ficar tranqüila, porque embora a pessoa do homenageado merecesse alongado discurso, penso que me foge o direito de enfastiar o atento auditório, dizendo mais do que deveria.

Já que recordar é viver, relembremos em rápidos traços o que tem sido a vida de nosso novo titular.

1946. Prestávamos os vestibulares para esta Casa. Entrávamos, pelo portal da frente, contemplando os vultos de Castro Alves, Fagundes Varela e Álvares de Azevedo. Eu já era professor de Latim, no Colégio Estadual, e, mesmo assim, estava apreensivo com a prova que tínhamos de fazer.

Lembro-me daquele dia, terror dos estudantes, que teriam de decifrar trechos difíceis de uma língua, que não mais se falava.

O trecho sorteado foi um passo dificílimo de Ovídio, extraído das Metamorfoses, referente ao Dilúvio, no momento 
em que se encontram Deucalião e Pirra. "Dixerat et flebant" - dissera e choravam. Fora escolhido - depois soubemos pelo Professor Miguel Reale, que, com estes versos insuperáveis, queria testar se os candidatos decoravam ou se sabiam traduzir a língua latina, já que os verbos, em tempos e pessoas diferentes, pretérito perfeito do singular e pretérito imperfeito no singular, só poderiam ser identificados por quem conhecesse a gramática latina. Não pelo improvisador de última hora, pelo decorador.

Era uma terça-feira, de manhã, bem me lembro.

Ao sair, vi, naquele instante, agora remoto, um rapaz magrinho, tímido, sobraçando o clássico e pesado Dicionário Santos Saraiva, muito divulgado, na época.

Perguntou-me, quase a sussurrar: "O Senhor, que é professor de Latim, poderia verificar se acertei mais ou menos a tradução"? Em poucas palavras reconstituiu o trecho e manifestei-lhe a convicção de que apreendera bem o pensamento do sulmonense. Tranqüilizei-o.

Foi este o meu primeiro e inesquecível encontro com João Bernardino: Garcia Gonzaga - o nosso homenageado desta noite.

Passaram-se, como se passam depressa, os cinco anos de Faculdade.

As aulas, os exames, os professores, a tradição da casa, tudo envolvendo a todos e a cada um.

E a amizade de toda turma com João Bernardino se foi consolidando e estreitando, acrescendo ainda que ele era "o sobrinho do Basileu", mestre que empolgaria toda a turma, a partir do segundo ano, professor notável que marcou para sempre a nossa geração.

Esta convivência com Bernardino prolongou-se pelos cinco anos do curso. 
Formâmo-nos. Cada um de nós tomou seu rumo, seguindo destinos diferentes, mas sempre cruzados, já que a Academia, referencial afetivo obrigatório, se interpunha na lembran ça carinhosa de todos nós.

Nos encontros freqüentes de colegas, a figura simpática; agora menos tímida do João, estava sempre presente. E aquelas reuniões periódicas dos colegas de Direito me surpreendiam e maravilhavam. Era uma família que tinha uma fonte comum.

Bem antes, em 1946, quando ingressei nesta Casa, eu já era formado pela Faculdade de Filosofia, Ciências e Letras, onde tivera a honra de ser colega de Sílvio Rodrigues, hoje meu querido e sábio colega de Congregação.

Pois bem, por mais incrível que pareça, nunca houvera, como até agora nunca houve, uma reunião daqueles colegas da outra Escola, em 35 anos de formados, pois àqueles formados falta o espírito perene das Arcadas, que sobrepaira em cada momento de nossas vidas e marca a conduta de cada um.

Já disse, numa outra ocasião, que o espírito que liga os egressos da Academia me lembra aquela lenda da mitologia helênica, em que o poderoso gigante Géia, quando sentia que as forças lhe faleciam, apoiava-se à terra-mater com as mãos, e a força telúrica lhe fornecia novo alento, como se o planeta fosse formidável bateria que recarregasse o motor desfalecido daquele corpo legendário, mas que se exauria nos embates que travara.

Também nós, nesta São Paulo trepidante, cidade desumana e desagregadora, quando nos sentimos deprimidos e exaustos, passamos pela Academia, olhamos para o velho prédio, entramos, damos uma volta pelo pátio histórico, ouvimos o borbulhar dos estudantes e sentimos vida nova, forças novas para, como o gigante da lenda, batalhar outras batalhas e pugnar outras pugnas. 
1953. João Bernardino encontra a companheira de sua vida - Dona Jeanine -, aqui presente, amiga de todas as hor ras, a dar-lhe aquela retaguarda importante do lar bem constituído, alicerce seguro de que o homem tanto necessita para triunfar na vida.

1957. Pela primeira vez, João Bernardino bate às portas desta Casa, apresentando a monografia $O$ crime de omissão de socorro. Eu estive presente nessa ocasião memorável e assisti ao embate.

Fazia parte da Banca o professor Canuto Mendes de Almeida, homem bom e justo, que, por exceção, resolveu argüir o candidato, propondo-lhe a seguinte pergunta, até hoje insolúvel: "Qual a diferença entre crime e contravenção"?

Ia o candidato tentar a resposta, quando o argüente, interrompendo-o, disserta longa e eruditamente sobre o tema, embevecendo a platéia, como ainda nos embevece, agora, quando, nos intervalos, monopoliza a conversa na sala dos professores, prendendo-nos durante os quinze minutos entre uma aula e outra.

Havia, porém, outro argüiente, na Comissão, o professor Soares de Mello, que enregelou os amigos de João Bernardino, ao principiar: "Há alguns anos, quando prestei concurso para a Cátedra, entre os examinadores estava o pai de Vossa Senhoria que, por sinal, foi o mais severo de meus julgadores, o mais implacável dos argüentes. Como o Destino dá muitas voltas, aqui estou agora, na mesma sala, mas agora sou eu o examinador. Portanto. ."

Para espanto de todos, entretanto, o professor Soares de Mello não se desforrou no candidato, aprovando-o, até, com elevada nota. João é aprovado, mas não descansa sobre os louros. "Hei de ser titular da Escola" - confessou-me várias vezes. 
Tempos depois, escrevendo magnífica tese sobre Entorpecentes, João Bernardino se torna titular de Direito Penal da Pontifícia Universidade Católica, na qual, pouco depois, vê seu nome escolhido como Diretor.

Por essa época, faz interessante, mas desisteressada e pura pesquisa sobre o direito penal, entre os povos primitivos, e nos presenteia com a monografia $O$ direito penal indígena.

Advogando intensamente, especializa-se no campo do direito administrativo, onde consegue novas, sucessivas e merecidas vitórias, tornando-se conhecido como advogado militante, em questões de direito público. Eu mesmo, que cultivo o direito administrativo, tornei-me seu cliente, quando julguei ter direitos subjetivos públicos, oponíveis ao Estado.

João Bernardino Garcia Gonzaga é convocado para outras missões, nem todas agradáveis, como quando foi desig. nado pela Diretoria da Escola, em 1968, para presidir à Comissão de Inquérito, que iria ouvir os estudantes que tinham ocupado o prédio da Faculdade, ao meu lado e ao lado de outro nossio colega de Congregação - o professor Geraldo Camargo Vidigal. Por essa ocasião, revelou-se ponderado, equilibrado, empenhado em apurar a verdade, sem se intimidar oom as ameaças de que era alvo a Comissão e sem se melindrar coń a atitude irreverente de alguns dos inquiridos. Era juiz. Perguntava. Ouvia. Julgava.

Mais uma vez inclinei-me diante da sabedoria de João Bernardino.

Parece-me, quando o analiso, que para a personalidade invulgar de Bernardino convergem três traços que partem $\mathrm{d} c$ três pontos diferentes da Europa: a reserva distante do bri. tânico, a graça inconfundível gaulesa, a ironia fina dos povos itálicos. E todas essas qualidades num. homem só! 
Só quem o conhece é que pode ver a dimensão incomensurável de Bernardino, escondida sob polida reserva, muro penetrável apenas a alguns eleitos que com ele privam.

1976. Trinta anos são decomidos e Bernardino bate pela segunda vez - e também vitoriosamente - às portas desta Academia, inscrevendo-se com notável e alentada monografia - Violação do Segredo Profissional -, obra segura, de consulta obrigatória, por todos quantos, daqui por diante, versem aquele complicado tema.

Educador de primeira, que não se preocupa, tão-só, em transmitir as noções da matéria lecionada, João Bernardino realiza a tarefa sublime do mestre que plasma a alma do educando, lembrando-nos a figura descrita pelo Padre Antonio Vieira, naquela página antológica, em que o seiscentista deslumbrava as platéias da época, no Sermão do Espírito Santo: "Vede o que faz em uma pedra a arte. Arranca o estatuário uma pedra dessas montanhas, tosca, bruta, dura, informe; e depois que desbastou o mais grosso toma o maço e o cinzel na mão e começa a formar um homem, primeiro, membro a membro, depois, feição por feição, até a mais miúda: ondeia-lhe os cabelos, alisa-lhe a testa, rasga-lhe os olhos, afila-lhe o nariz, abre-lhe a boca, avulta-lhe as faces, torneia-lhe o pescoço, estende-lhe os braços, espalma-lhe as mãos, divide-lhe os dedos, lança-lhe as vestes: aqui desprega, ali arruga, acolá recama, e fica um homem perfeito, e talvez um santo, que se pode por no altar" (Cf. edição de 1683, v. III, p. 419-420)

Assim procede João Bernardino com seus alunos: modela caracteres, forma o educando, prepara-o para a vida, não apenas para a escola. Não se limita à informação, transmitindo conteúdos de direito criminal. Forma o acadêmico. E, antes de tudo, um educador modelar.

Cumprindo o prometido, não me alongarei mais, embora muito mais houvesse para dizer a respeito de nosso homenageado. 
Agradeço a honrosa missão que me foi confiada. Ao fazêlo, tenho a certeza certa, a convicção mais absoluta de que a conquista da Cátedra não foi para o novo professor um ponto de chegada, mas um ponto de partida, marco inicial de nova trajetória contínua, nesta carreira pontilhada de triunfos, em! que este novo astro brilhará com um fulgor cada vez mais brilhante no mundo luminoso do direito e da justiça.

\section{João Bernardino Garcia Gonzaga}

\section{Agradece a Saudação dos Professores.}

Tendo-me tornado Professor Titular da nossa Academia, nada mais espero nem almejo, nesta vida, em matéria de glórias e honrarias.

Comecei cedo, menino ainda, como aprendiz no escritório do Mestre Basileu Garcia, de quem logo depois, durante três anos, fui também aluno e, mais adiante, assistente em sua cátedra.

Eu trazia já, da casa paterna, sólida estrutura. Mas foi com Basileu Garcia que assegurei minha formação. Por suas mãos, a um só tempo, me converti em advogado e professor.

Agora o sucedo no cargo, e isso, se é verdade que me ufana, deixa-me fundamente apreensivo. Como discípulo seu que sou, tendo-o acompanhado em todos os setores da vida, pública e particular, que não se perca o meu fiel testemunho. Trata-se não apenas de um advogado, entre outros. É o advogado modelo. Durante anos e anos eu o vi exercer seu ministério. Dotado de excepcional vocação profissional, com um estilo encantador e habilíssimo condutor de processos, as notas marcantes da sua personalidade são a lucidez, o denodo, a obsessiva honestidade. Jamais poderiam suspeitar, aqueles que the confiam suas causas, o quanto por eles se preocupa e trabalha. 
Como Professor, a mensagem que transmite a nós, seus alunos, é a de um realismo singelo. Aborrecem-no as expressões pomposas, as frases pedantes, as atitudes rebuscadas, as idéias obscuras que se lançam com suposta profundidade. As teorias, ele as absorve, filtra-lhes o que há nelas de eventualmente bom e útil, para assim torná-las simples. Nunca se deixa enganar. $O$ Direito, nas suas mãos, se torna autêntico, participa da vida efetiva, entrosa-se com o dia a dia.

Sua aposentadoria foi uma grande perda para nossa Escola. Eu o sucedo, mas não o substituo. Dificilmente alguém poderia fazê-lo.

Assumo aqui o meu posto num momento difícil, porque estamos em pleno tempo de reformas. Desta Casa se espera que, prosseguindo na sua vocação histórica, trace as diretrizes orientadoras.

Cada vez mais ouço falar em crise do Direito. Não me agrada a palavra, acho-a, no fundo, enganadora. Contém, para nós juristas, um sabor de derrota. Ainda há pouco, relendo excelente coletânea de estudos feitos em torno da obra de Ripert, impressionaram-me desde logo os títulos que se enfileiram no índice: A Ambigüidade do Direito Contemporâneo; Crise do Direito e Crise Mundial; A Crise do Direito na Sociedade Contemporânea; A Crise do Estado Moderno; A Crise da Personalidade do Estado; A Crise da Justiça. E para concluir melancolicamente, este trabalho de Carnelutti: A Morte do Direito.

Enfim, derrocada completa, parece que nada se salva...

Talvez a propalada crise do Direito se reduza, afinal de contas, a um drama pessoal nosso, que nos sentimos compelidos a rever conceitos, a fim de nos adequarmos ao presente e nos projetarmos no futuro.

No perpétuo avançar das instituições, of fluxo possui rítimos diversos, sucedem-se mudanças lentas e rápidas. Antes, 
em épocas de prolongada paz social, os juristas puderam repousar à sombra das suas arquiteturas conceituais, compostas de normas genéricas e abstratas, imaginadas como contendo virtualmente a solução de todos os casos que se iriam apresentar no ambiente social. A eles bastavam os instrumentos da sua lógica para deslindar diretamente cada problema.

Mas agora sentimos que, à nossa volta, tudo se convulsiona, e isso nos angustia, quando em vez deve incitar à luta. Urge que nos ativemos, justamente porque essencial função do Direito é garantir o ordenado desenvolvimento da vida social.

O mundo, até há pouco, esteve sempre dividido em duas faixas marcantes. Pequena camada superior, das pessoas educadas, ou cultas, que detinham o poder. Aí, apenas, se estabeleciam os diálogos, traçavam-se regras, a seguir transmitidas para baixo, ou seja, para a grande massa, que a elas se adequava.

De repente, o panorama entrou a mudar, com desnorteante rapidez, mercê principalmente do alastramento dos meios de comunicação. No momento em que as idéias e as notícias passaram a difundir-se por áreas cada vez mais amplas da população, como contra-partida expandiu-se o número dos que também se querem fazer ouvir.

Talvez um dos mais característicos fenômenos da fase histórica atual seja este: o fraco percebeu que pode enfrentar, igualar-se e até mesmo suplantar o forte. Acontece com indivíduos, grupos, povos e nações. $\mathrm{O}$ recente conflito do Vietnã o provou com eloquiência. Constituiu uma lição, cujas consequiências todas ainda não conseguimos captar.

O ignorante, hoje, contesta o sábio. O pobre descobre que deve ter os mesmos benefícios do rico. Ãs vezes com justiça, outras não, todos se precipitam para um nivelamento geral. 
No momento pois em que os homens das multidões começaram a levantar-se; em que sobreveio avassalador aumento das pessoas que falam, que manifestam seus pensamentos, que discutem as regras, que exigem participação na vida, - inúmeros antigos hábitos e valores, tão bem assentados, se estilhaçaram.

A coletividade se agita, muitos querem ser atendidos. As ciências, a tecnologia, a propaganda, passaram' então a trabalhar freneticamente. Tornaram-se obsessivas as preocupações com matérias como urbanismo, saúde pública, engenharia dos transportes, distribuição de bens de consumo. Em meio a tão confuso movimento, que precisa ser coordenado, despontaram as figuras do tecnocrata, do sociólogo, do economista, para assumirem a liderança.

Os bacharéis, no Brasil, já desempenharam uma grande missão eclética, cobrindo vários campos que se achavam outrora desguarnecidos. Fomos filósofos, sociólogos e literatos; políticos, economistas, administradores, poetas. Muito nos deve o País pelo que, por ele, fizemos.

Mas esse tempo desapareceu, e agora começa a desenvolver-se um máu e prescindível fenômeno inverso. Todas as áreas do saber possuem seus competentes cultores. Acossados todavia pela premente necessidade de reformas, eles passaram a invadir nosso domínio. Sentimos que o Direito, enquanto complexo de normas positivas, nos está escapando das mãos. Profissionais dos mais variados setores se puseram a legislar apressadamente e sozinhos, como se pudessem prescindir da nossa ajuda. Sem ao menos perceberem que a solução de certo problema técnico está muitas vezes inseparavelmente entranhada com a solução de um problema jurídico.

Faltam, a vários desses improvisados disciplinadores, não só a sensibilidade, a argúcia, em suma a particular formação cultural do jurista. Principalmente, com frequiência não po- 
dem ter a visão global que permite sopesar valores e que possibilita construir o Direito como um todo harmônico e justo.

Por isso, sim, caberá falar em crise, que pode ser acidental e passageira. A rossa legislação parece que ameaça resvalar para o caos. Depende agora de saber como os juristas irão reagir, em que medida conseguirão reassumir seu encargo.

O mundo atual não tolera atitudes de êxtase contemplativo, mas o ritmo é de frenesi. A orquestra deixou de soar andante moderato e já entrou, há muito, no allegro energico e passionato. Não nos equivoquemos porém. Os convulsivos processos de transformação, que se estão operando no âmbito do Direito, não são sinais de doença, mas de vitalidade. Não estamos no campo da patologia, e sim da fisiologia.

O que resta pois verificar, tão-só, é se as mudanças se desenvolverão à nossa revelia, ou se manteremos o comando das funções que nos cabem. Temos de sair em busca dos problemas novos, analisá-los e compreendê-los, para em seguida ditar o competente tratamento jurídico. Mas a velocidade tornou-se muito grande, de sorte que, como sucede com os veículos nas estradas, carece acender os faróis altos, para bem enxergar o que está à nossa frente, e ver longe.

Esta Faculdade, sempre atenta e pioneira, logo começou a preparar-se para o embate, alargando o seu campo de ensino.

De fato, o começo de tudo depende de nós, professores. Há toda uma efervescência pelo mundo, variados e férteis setores de trabalho surgem e se expandem. Até mesmo a criminalidade se afeiçoa aos modernos sistemas, criando problemas antes insuspeitados.

Cumpre portanto que formemos bacharéis aptos a bem representarem o Direito em toda parte. Precisamos continuar abrindo novos cursos, com disciplinas diversas, mormente em nível de pós-graduação ou de especialização. 
Para esse fervor de progresso, que a nós todos empolga, haverá sempre meu apoio.

Aqui estudei, orientado por excelentes mestres. Quando, há vinte e dois anos, fui admitido no corpo docente, como tímido e bisonho auxiliar de ensino, receberam-me, todos os professores, de braços abertos. Desde entāo, sempre encontrei à minha volta, nesta Casa, um ambiente cordial, de trabalho sério, de enternecedor idealismo.

Tenho pois imensa dívida de gratidão a resgatar, e estejam certos de que procurarei fazê-lo. 